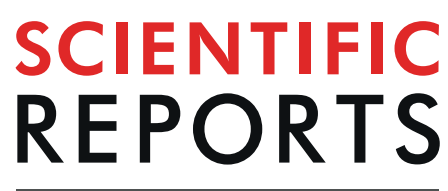

natureresearch

\title{
Daily Satellite Observations of Methane from Oil and Gas Production Regions in the United States
}

\author{
Joost A. de Gouw $\mathbb{1}^{1,2,7^{*}}$, J. Pepijn Veefkind ${ }^{3,4,7}$, Esther Roosenbrand ${ }^{1,4}$, Barbara Dix ${ }^{1}$, \\ John C. Lin ${ }^{5}$, Jochen Landgraf ${ }^{6}$ \& Pieternel F. Levelt ${ }^{3,4}$
}

Production of oil and natural gas in North America is at an all-time high due to the development and use of horizontal drilling and hydraulic fracturing. Methane emissions associated with this industrial activity are a concern because of the contribution to climate radiative forcing. We present new measurements from the space-based TROPOspheric Monitoring Instrument (TROPOMI) launched in 2017 that show methane enhancements over production regions in the United States. In the Uintah Basin in Utah, TROPOMI methane columns correlated with in-situ measurements, and the highest columns were observed over the deepest parts of the basin, consistent with the accumulation of emissions underneath inversions. In the Permian Basin in Texas and New Mexico, methane columns showed maxima over regions with the highest natural gas production and were correlated with nitrogen-dioxide columns at a ratio that is consistent with results from in-situ airborne measurements. The improved detail provided by TROPOMI will likely enable the timely monitoring from space of methane emissions associated with oil and natural gas production.

Methane is the second most important anthropogenic greenhouse gas in the atmosphere after carbon dioxide ${ }^{1}$. Methane emissions are related to (i) the production of fossil fuels, i.e. crude oil, natural gas and coal, and can also be released from natural seeps, (ii) microbial processes in wetlands, rice cultivation, livestock, landfills and termites, and (iii) biomass burning ${ }^{2}$. Because of the imbalance between methane sources and sinks, the atmospheric mixing ratio has increased from a pre-industrial value of $722 \mathrm{ppbv}^{1}$ to the current global average of approximately $1850 \mathrm{ppbv}^{3}$. As the atmospheric lifetime of methane is relatively short at 9.1 years ${ }^{1}$, a reduction in methane emissions would lower the combined radiative forcing from greenhouse gases on a timescale of years and is therefore a relatively efficient option to mitigate climate change.

Methane emissions associated with the production of fossil fuels (coal, oil and natural gas) constitute about $24 \%$ of the global emissions of methane and a larger fraction of the anthropogenic emissions. The global emissions from this industry have stayed relatively constant since 1985 even as the global production of fossil fuels increased over this same time period ${ }^{2}$. Methane emissions from the U.S. oil and natural gas supply chain have received much recent attention and are estimated to be $2.3 \%$ of gross U.S. gas production ${ }^{4}$ and $41 \%$ of the anthropogenic U.S. emissions ${ }^{5}$. The long-term trends in U.S. emissions of methane are the subject of some debate, with one study finding a $30 \%$ increase between $2002-2014^{6}$, and another finding no significant trends between $2006-2015^{7}$.

Global measurements of methane are made from a network of ground-based and airborne in-situ measurements ${ }^{8}$. These measurements are mostly made away from sources to reflect background concentrations. Measurements of methane emissions in oil and gas production areas have been made using surface monitors 9,10 and from research aircraft ${ }^{11-13}$. The latter are labor intensive and only provide snapshots of emissions, which

\footnotetext{
${ }^{1}$ Cooperative Institute for Research in Environmental Sciences, University of Colorado, Boulder, CO, United States. ${ }^{2}$ Department of Chemistry, University of Colorado, Boulder, CO, United States. ${ }^{3}$ Royal Netherlands Meteorological Institute, de Bilt, The Netherlands. ${ }^{4}$ Faculty of Civil Engineering and Geosciences, Delft University of Technology, Delft, The Netherlands. ${ }^{5}$ Department of Atmospheric Sciences, University of Utah, Salt Lake City, UT, United States. ${ }^{6}$ SRON Netherlands Institute for Space Research, Utrecht, The Netherlands. ${ }^{7}$ These authors contributed equally: Joost A. de Gouw and J. Pepijn Veefkind. *email: Joost.deGouw@colorado.edu
} 
may be an issue as episodic, large emissions can represent a relatively large fraction of the total ${ }^{14}$. This calls for more frequent, basin-wide monitoring of emissions, which explains the interest in methane measurements using space-based sensors. However, observing methane from oil and gas operations from space has been challenging. Schneising et al. derived methane emissions from two oil producing regions, the Bakken and Eagle Ford, using data from the SCIAMACHY instrument ${ }^{15}$. Kort et al. described the observation in SCIAMACHY data of a hotspot in methane over the Four Corners region, a region with natural gas and coal-bed methane production ${ }^{16}$. Turner et al. used data from the GOSAT instrument to describe trends in U.S. methane emissions but could not attribute the trends to a specific sector ${ }^{6}$. All of these studies presented satellite measurements of methane that were averaged over a year or more. One study that used observations from single satellite overpasses was reported by Thompson et al. following the Aliso Canyon blow-out ${ }^{17}$, which was one of the largest accidental releases of methane in recent history ${ }^{18}$. Similarly large emissions of methane in Turkmenistan were recently reported using data from GHGSat and TROPOMI ${ }^{19}$.

The TROPOspheric Monitoring Instrument (TROPOMI) is the sole instrument on the EU Copernicus Sentinel 5 Precursor satellite that was launched in October 2017. In comparison with its predecessor, the Ozone Monitoring Instrument $(\mathrm{OMI})^{20}$, TROPOMI has an improved spatial resolution of up to $7 \times 3.5 \mathrm{~km}^{2}$ and also added a short-wave infrared radiation (SWIR) band that allows the detection of methane and carbon monoxide ${ }^{21}$. The TROPOMI measurements of methane have been compared with those from the GOSAT instrument and were found to be in good agreement ${ }^{22}$. Here, we study the enhancements in methane observed over two oil and gas production regions in the U.S., the Uintah basin in Utah and the Permian Basin on the border of Texas and New Mexico. Using corroborating evidence from ground-based and airborne measurements, we show that the observed methane enhancements in single overpasses can be attributed to emissions into the boundary layer from oil and natural gas production. These results suggest that the future determination of regional methane emissions with a high time resolution and soon after the time of emission will be feasible.

\section{Results}

TROPOMI observations. Average methane columns over the contiguous U.S. between 1 December 2018 and 31 March 2019 are shown in Fig. 1. The number of TROPOMI retrievals per grid box during this period is shown in Fig. S1 and was limited over some regions due to cloud cover, low surface albedo, topography and other factors that affect the data quality. Enhancements in methane columns are for example observed:

- Over the Central Valley of California, a region with strong methane emissions from agriculture (both livestock and rice cultivation) and from oil and natural gas production. The enhancements were particularly clear in December 2018 and January 2019, as a result of wintertime inversions that trap emitted methane in the boundary layer.

- In the Uintah basin in Utah in the northeastern corner of the state. This is a region where strong inversions can trap emissions from oil and gas production in the winter. Accordingly, the enhancements were particularly clear in December 2018.

- Over Texas, which has several oil and gas producing regions. Both oil and gas are produced in the Permian Basin in the Southeast corner of New Mexico and the adjacent parts of Texas, and in the Eagle Ford south of San Antonio. Natural gas production also takes place in the Barnett Shale west of Dallas - Fort Worth, and in the Haynesville on the border of Texas and Louisiana.

- Over several states with intense agricultural production of corn and soybean ${ }^{23}$ ranging from North Dakota through Minnesota, Illinois and Ohio as well as the Mississippi Delta region. Rather than an actual emission of methane, we suspect that retrieval biases due to low surface albedo in the winter, when the agricultural soils are bare, may play a role and need to be further investigated.

- Over Florida, which may be related to emissions from wetlands.

The San Juan basin in the northwestern part of New Mexico does not show up consistently in the TROPOMI data so far, although enhancements at the northern end of the basin were observed on two days in January 2019 (Fig. S2). A previous study identified a hot spot in methane in this basin using data from SCIAMACHY ${ }^{16}$.

Average tropospheric $\mathrm{NO}_{2}$ columns between 1 December 2018 and 31 March 2019 are also shown in Fig. 1. In this case, the strongest enhancements are observed over metropolitan areas such as New York City, Chicago, Denver, Houston, Los Angeles and many others. Enhanced $\mathrm{NO}_{2}$ columns are also observed over oil and gas producing regions, most clearly over the Permian Basin and Eagle Ford in Texas, and the Bakken in North Dakota. Enhanced $\mathrm{NO}_{2}$ over these regions was previously identified in the OMI data ${ }^{24}$.

The methane columns shown in Fig. 1 have not been validated in detail. A comparison with GOSAT data was previously published ${ }^{22}$ and a comparison with the measurements by the Total Carbon Column Observing Network (TCCON) is currently in progress. We include here a comparison between TROPOMI measurements that are co-located with the Lamont TCCON site in Oklahoma within a 300-km radius (Fig. S3). The dynamic range in methane columns over the comparison period was limited, but the two data sets both show periods with enhanced columns in August 2018 and in October-December 2018, and were correlated with a linear correlation coefficient, $r$, of 0.6. The average bias between the TROPOMI and Lamont TCCON data sets was $-7.5 \pm 9.9 \mathrm{ppbv}$, where the error represents the $1-\sigma$ variability in the bias from individual days.

The accuracy of the TROPOMI methane column product for low surface albedo needs further investigation and so data included in this paper are all limited to a surface albedo higher than 0.05, except for Fig. S2 where an albedo threshold of 0.03 was applied. Methane column mixing ratios over the Great Lakes region and into Canada are occasionally lower than the surface values and possibly affected by low tropopause heights and stratospheric air masses with reduced methane. Nevertheless, the column enhancements over Utah and Texas appear to be 

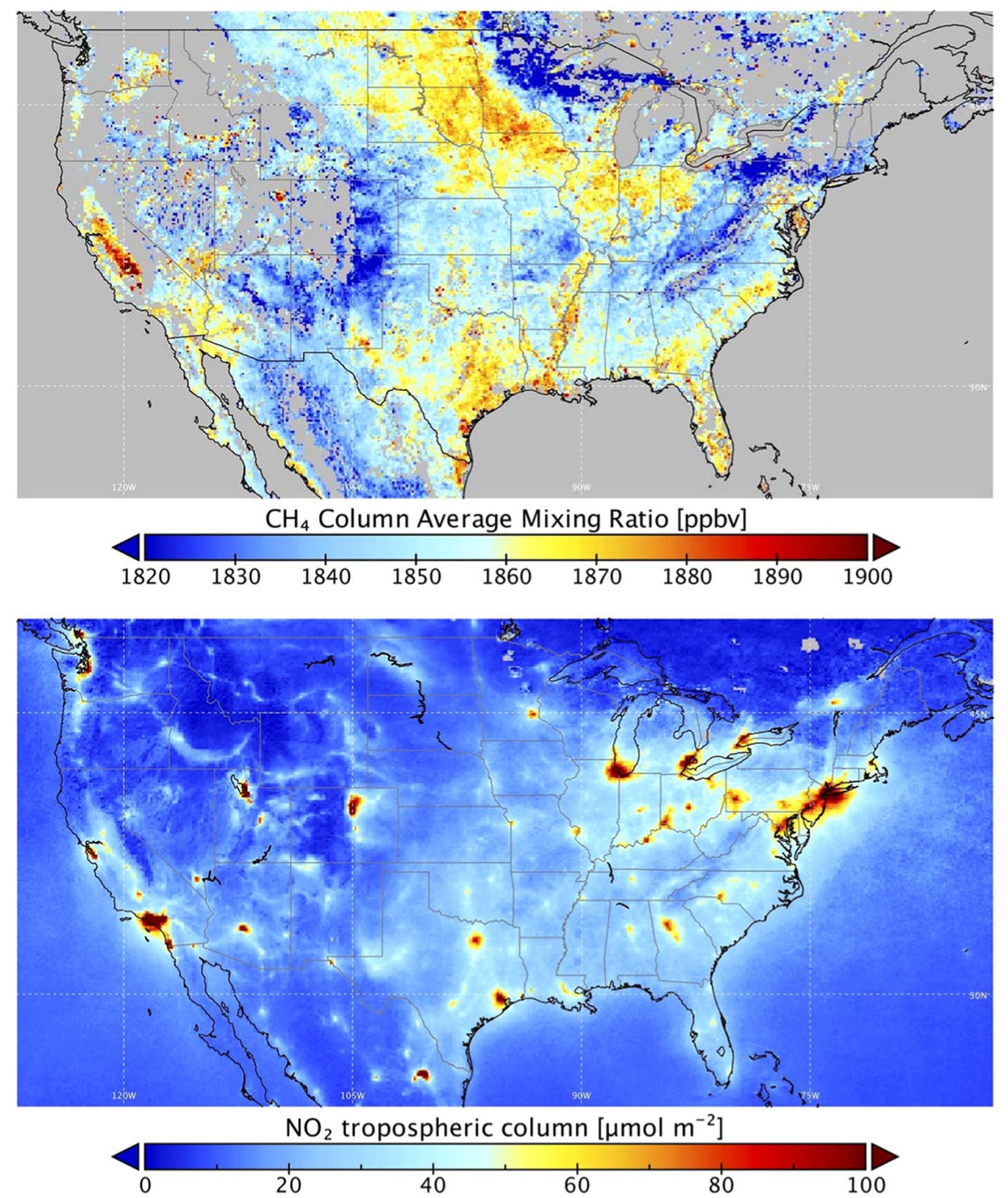

Figure 1. Average TROPOMI columns for (top) methane and (bottom) tropospheric $\mathrm{NO}_{2}$ over the contiguous United States between 1 December 2018 and 31 March 2019. Retrieved columns have been binned on a $0.1^{\circ} \times 0.125^{\circ}$ latitude-longitude grid for this analysis.

readily attributable to emissions associated with oil and gas production, and this hypothesis is evaluated in the next two sections.

Uintah basin. The Uintah Basin in Utah is a smaller natural gas and, to a lesser extent, oil producing region in the northeastern part of Utah. Drilling activity has declined since 2008 and natural gas production is currently decreasing (Fig. S4). The basin is surrounded by mountains and atmospheric studies in the region were sparked by the occurrence of winter ozone formation ${ }^{25,26}$. This unusual phenomenon occurs when emissions from oil and gas production accumulate under cold-pool conditions strengthened by a snow cover, and react photochemically over the course of days to build up ozone to levels that far exceed other polluted regions of the U.S.

The TROPOMI methane measurements show a clear hotspot over the Uintah basin (Fig. 2A). Enhanced methane columns were observed on the south side and deeper part of the basin, where most of the oil and natural gas wells are situated ${ }^{11}$. Data gaps in the TROPOMI data are caused by clouds, topographic features and low surface albedo. The methane hotspot in the Uintah Basin became less obvious from December 2018 through March 2019 as the cold-pool conditions that trap emissions in the basin became less prevalent (Fig. S5). $\mathrm{NO}_{2}$ columns over the Uintah Basin are strongly affected by emissions from the Bonanza power plant ${ }^{26}$ and are not included in this analysis.

Methane has been measured in-situ in the basin since 2015 at three different locations indicated in Fig. 2A. The Horsepool and Roosevelt monitors are situated at lower elevation in the basin and are frequently exposed to high methane in the winter when emissions are trapped under cold-pool conditions. The Fruitland monitor is situated at a higher elevation and does not see similarly high methane enhancements ${ }^{27}$. Figure $2 \mathrm{~B}$ compares the TROPOMI methane columns between December 2018 and March 2019 with data from the three monitors. 

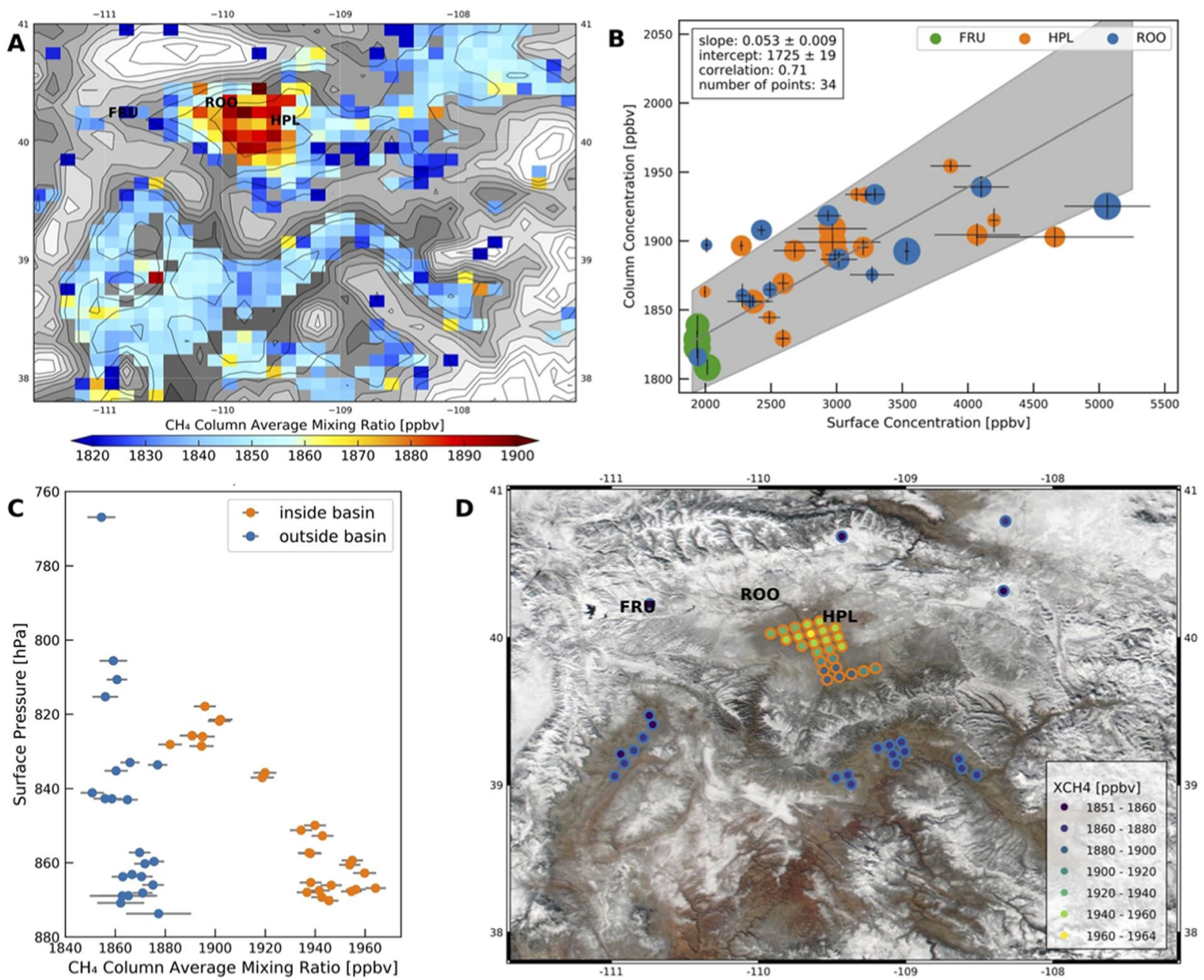

Figure 2. TROPOMI methane observations over the Uintah Basin in Utah. (A) Average methane columns from 1 December 2018 through 31 March 2019. The grey shaded background shows the surface elevation from the GMTED $0.125^{\circ}$ digital elevation map. The contour lines indicate 50 -meter steps in the surface elevation. (B) Comparison between the TROPOMI methane columns with the coincident in-situ measurements at Horsepool (HPL), Roosevelt (ROO) and Fruitland (FRU). The size of the symbols indicates the distance between the satellite ground pixel and the surface monitor, where large symbols indicate better collocation. Error bars in surface concentrations represent the standard deviation in the 60-min mean centered on the TROPOMI overpass time. Error bars in the column concentration represent $2 \times$ the reported precision of the retrieval as recommended. (C) Methane columns on 9 December 2018 as a function of the surface pressure, for ground pixels inside the Uintah basin (orange) and outside the basin (blue). (D) Location of the methane column measurements shown in panel $\mathrm{C}$, where the inside of the symbols indicates the $\mathrm{CH}_{4}$ mixing ratio and the outside is orange for pixels inside the Uintah basin, and blue outside the basin. Methane is not retrieved over pixels with too much variability in the terrain elevation, which explains the many missing pixels in panel A and D.

The in-situ measurements were averaged over a 60-min interval centered on the overpass time of the TROPOMI instrument. TROPOMI data were limited to those pixels that were within $30 \mathrm{~km}$ of the monitor, with the size of the symbol representing the proximity. Data were also selected for surface albedos $>0.05$. The column average methane mixing ratios from TROPOMI correlate with the in-situ measurements with a correlation coefficient of 0.71. The effect of selecting for surface albedo is shown in Fig. S6. A less strict criterion results in more outliers, but the correlation between the column and in-situ measurements remains.

Figure $2 \mathrm{~B}$ shows a linear regression slope between the column-averaged and surface methane mixing ratios of 0.053 . This value is much lower than one, because methane is only enhanced in a shallow boundary layer. Assuming a tropopause altitude of $\sim 10 \mathrm{~km}$ and a surface altitude of $1.5 \mathrm{~km}$, this implies that methane accumulates in a layer of $\sim 450 \mathrm{~m}$ thick $(0.053 \times 8500 \mathrm{~m})$. This layer height is in the range of previous observations in the basin. During cold-pool conditions, the height of the polluted layer is lower initially $(200-300 \mathrm{~m})^{26}$ but can grow as cold-pool conditions persist and emissions gradually mix to higher elevations. Deeper boundary layers of more than $\sim 1500 \mathrm{~m}$ were also observed in the winter in the absence of cold-pool conditions ${ }^{11}$. More insight into the altitude distribution of the methane is obtained by plotting the column average mixing ratios of methane observed on a single day, 9 December 2018, as a function of the surface pressure, i.e. elevation (Fig. 2C), with the location of 

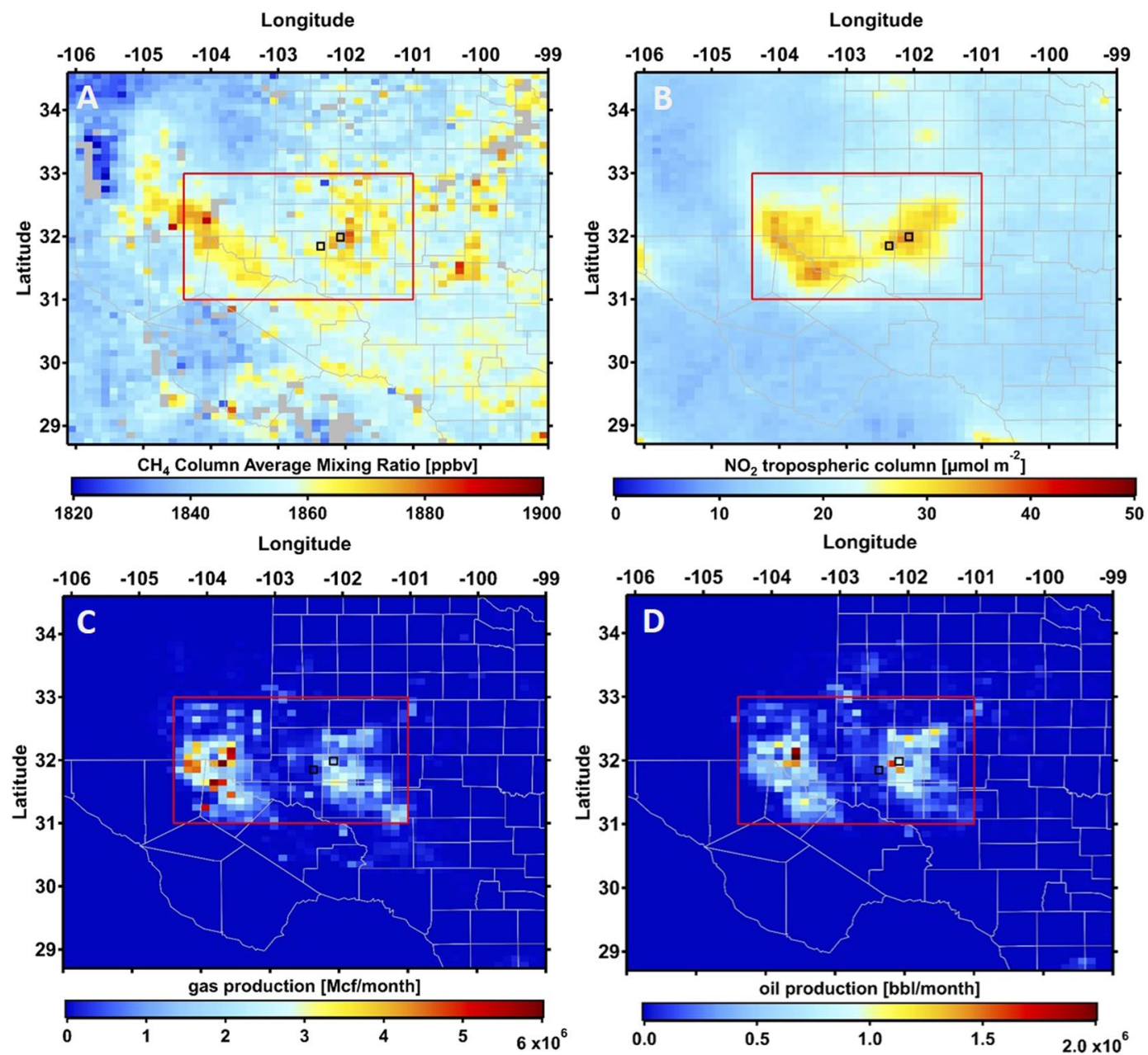

Figure 3. (A) TROPOMI methane and (B) tropospheric $\mathrm{NO}_{2}$ over the Permian basin averaged from 1 December 2018 through 31 August 2019. Panels C and D show the natural gas and oil production averaged over that same period. The locations of the largest cities in the region, Midland and Odessa, are indicated by the open squares in all 4 panels.

the columns shown in Fig. 2D. In the absence of local emissions, the column-averaged methane mixing ratios do depend slightly on surface elevation, which may explain the observations outside the basin, but the much stronger altitude dependence inside the basin can only be attributed to the build-up of methane in a shallow layer. This analysis also suggests that the depth of the layer with enhanced methane is $\sim 50 \mathrm{hPa}$ or $\sim 500 \mathrm{~m}$. It should be noted that the Uintah basin was snow-free on 9 December 2018 (Fig. 2D), so the inversion may not have been strong and the mixed layer deeper than during cold-pool conditions ${ }^{28}$.

We conclude that the TROPOMI hotspot observed over the Uintah Basin is caused by enhanced methane in the boundary layer in agreement with surface monitors. Continued surface and TROPOMI measurements over the Uintah Basin will be useful to further develop and evaluate emissions estimates under cold-pool conditions ${ }^{27}$, which can then be applied with more confidence for other, similar basins.

Permian basin. The Permian Basin in Texas and New Mexico has been a very large production region for both oil and gas in the United States for many years (Fig. S4). The region has seen increases in extraction of both oil and natural gas by unconventional means since 2010, i.e. horizontal drilling and hydraulic fracturing that allow extraction from shale and tight sands formations. Unlike the Bakken in North Dakota and the Eagle Ford in Texas, the Permian Basin did not see a decrease in oil production after the 2015 downturn in drilling and is currently developing very rapidly.

Figure 3 shows the methane and tropospheric $\mathrm{NO}_{2}$ columns over the Permian basin averaged over the 1 December 2018 through 31 August 2019 period. Natural gas and oil production volumes are shown in Fig. 3C,D. Both methane and $\mathrm{NO}_{2}$ show enhancements over the Delaware basin in the west, and the Midland basin in the eastern part of the Permian Basin. $\mathrm{NO}_{2}$ is also enhanced over Midland and Odessa, the two main cities in the region, but $\mathrm{NO}_{\mathrm{x}}$ emissions in these cities are clearly not the only source. Figure 4 illustrates the relationship between methane and oil and gas production in more detail. For each month between December 2018 and August 2019, we regressed gridded methane columns vs. gridded natural gas and oil production, and the best fits for each month are shown in Fig. 4. Examples of the individual fits are shown for August 2019 in Fig. S7. It is seen that pixels 

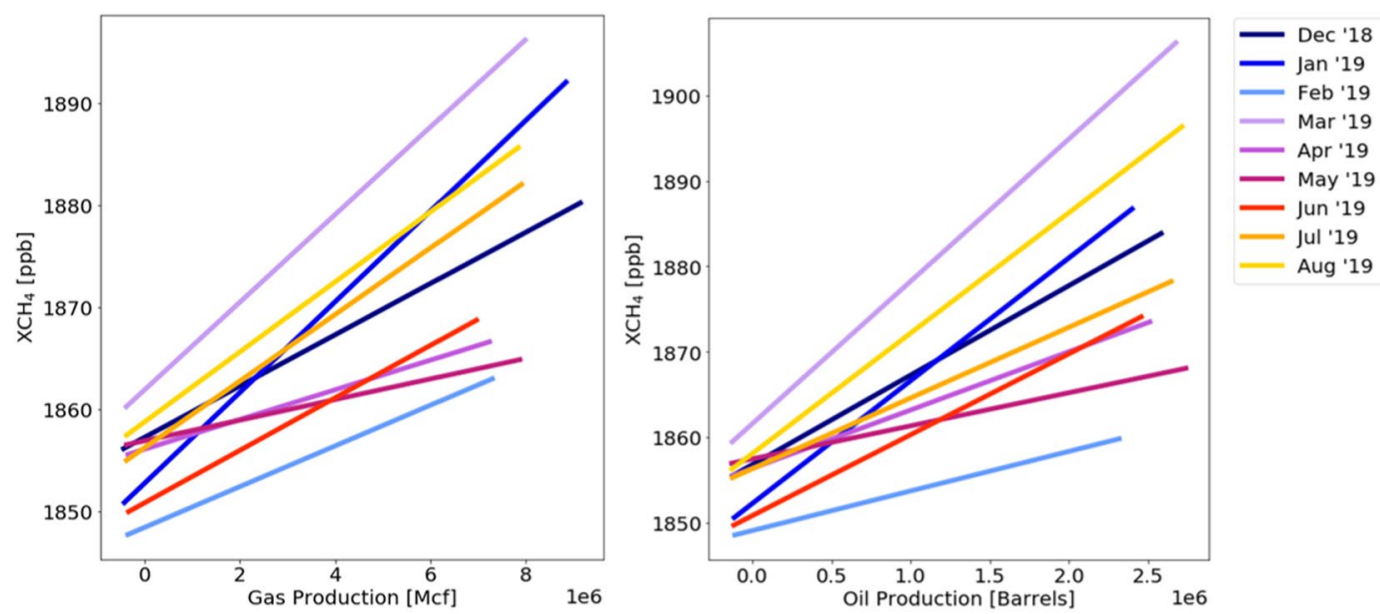

Figure 4. Average relationships between monthly averaged, gridded methane columns vs. natural gas (left) and vs. oil production (right) over the Permian Basin.

with higher production are associated with significantly higher methane columns, and that the slopes are similar between different months.

Using airborne measurements, it has been shown that methane and $\mathrm{NO}_{\mathrm{x}}$ emissions in oil and gas production regions are correlated ${ }^{29}$. While these two trace gases are not from the exact same sources, the emissions are collocated thereby causing their correlation in the atmosphere. For example, methane is released from the wellhead, separator and compressor on each well site, while $\mathrm{NO}_{\mathrm{x}}$ is released from internal combustion engines that are used to run this equipment ${ }^{30}$. All these parts of the infrastructure are sufficiently close to each other that their emissions appear to come from the same location when sampling at a distance. Also, while the emissions from each well site can be different, an average $\Delta \mathrm{NO}_{\mathrm{x}} / \Delta \mathrm{CH}_{4}$ ratio is observed when averaging over $100 \mathrm{~s}$ of sites. Here, $\Delta \mathrm{NO}_{\mathrm{x}}$ and $\Delta \mathrm{CH}_{4}$ refer to their enhancements over the background and are determined from the linear regression between their mixing ratios, with the background in methane signifying the background mixing ratio. During airborne measurements in 2015 in the Permian Basin, this ratio was observed to be $(9.0 \pm 0.2) \times 10^{-329}$.

The TROPOMI methane and $\mathrm{NO}_{2}$ columns in the Permian Basin were often found to be correlated on individual days. Examples are shown for 31 January 2019 in Fig. 5 and for 25 January 2019 in Fig. S8. Within a box that encompasses the Permian Basin indicated with the thick line, $\mathrm{NO}_{2}$ and methane correlated with a correlation coefficient of 0.81 on 31 January (Fig. 4C) and of 0.86 on 25 January (Fig. S8). No concurrent enhancements were seen for the aerosol optical thickness derived from the NPP VIIRS measurements, which were obtained within minutes from the TROPOMI overpass, ruling out an aerosol interference. In the December 2018-March 2019 period, $\mathrm{NO}_{2}$ and methane were correlated with $\mathrm{r}>0.4$ on 45 out of 55 days with available data.

The relation between the $\mathrm{NO}_{2}$ and $\mathrm{CH}_{4}$ in the boundary layer is assessed for each day for which more than $10 \mathrm{NO}_{2}-\mathrm{CH}_{4}$ data pairs are available. First, we subtract the background for both $\mathrm{NO}_{2}$ and $\mathrm{CH}_{4}$. The background is estimated as the 10th percentile of the values. Next, we convert the $\mathrm{NO}_{2}$ column and $\mathrm{CH}_{4}$ mixing ratios into boundary layer mixing ratios, by assuming a boundary layer thickness of $100 \mathrm{hPa}$. For $\mathrm{NO}_{2}$ this is done by converting the number concentration into a mixing ratio. For $\mathrm{CH}_{4}$ we rescale the column mixing ratio by the surface pressure divided by $100 \mathrm{hPa}$. We fit a linear relationship through the $\mathrm{NO}_{2}-\mathrm{CH}_{4}$ data points, using an orthogonal least-squares fit. Before applying this fit, we apply a scaling such that both $\mathrm{NO}_{2}$ and $\mathrm{CH}_{4}$ are in the range $0-1$. On 31 January, the $\Delta \mathrm{NO}_{2} / \Delta \mathrm{CH}_{4}$ ratio was found to be $(4.9 \pm 0.2) \times 10^{-3}$. The distribution in the $\Delta \mathrm{NO}_{2} / \Delta \mathrm{CH}_{4}$ ratios from all overpasses between 1 December 2018 and 31 March 2019 with $r>0.4$ is shown in Fig. 5D. Also added to this graph is the $\Delta \mathrm{NO}_{\mathrm{x}} / \Delta \mathrm{CH}_{4}$ ratio of $(9.0 \pm 0.2) \times 10^{-3}$ reported from airborne measurements in the Permian Basin $^{29}$. This ratio is at the high end of the $\Delta \mathrm{NO}_{2} / \Delta \mathrm{CH}_{4}$ ratios from TROPOMI, which is entirely reasonable given that $\mathrm{NO}_{\mathrm{x}}$ includes $\mathrm{NO}$ in addition to $\mathrm{NO}_{2}$, and because of photochemical removal, which can remove a fraction of $\mathrm{NO}_{\mathrm{x}}$ on the timescale of atmospheric transport across the basin.

We conclude that the TROPOMI methane enhancements observed over the Permian Basin are caused by emissions in the boundary layer that include those from oil and gas production. The TROPOMI data show separate enhancements over the eastern (Midland) and western (Delaware) parts of the Permian Basin, which can be explored in more detail when more data are available.

\section{Discussion}

Using methane and $\mathrm{NO}_{2}$ column measurements from the new TROPOMI instrument, we have shown that emissions from oil and gas production in the Uintah and Permian Basins can be observed in the data from individual overpasses. This is a vast improvement over measurements from previous satellite instruments, which typically needed to be averaged over a year or more to quantify trends and regional enhancements in methane emissions.

In the future, TROPOMI will likely allow the study of trends in methane and $\mathrm{NO}_{\mathrm{x}}$ emissions from oil and gas production. It will be of interest to look for the correlations between, on one hand, methane and $\mathrm{NO}_{2}$ columns with, on the other hand, proxies for industrial activity such as active drill rig counts, production volumes of oil, gas and condensate, and natural gas flare data. Such analyses may allow the relative importance of different 

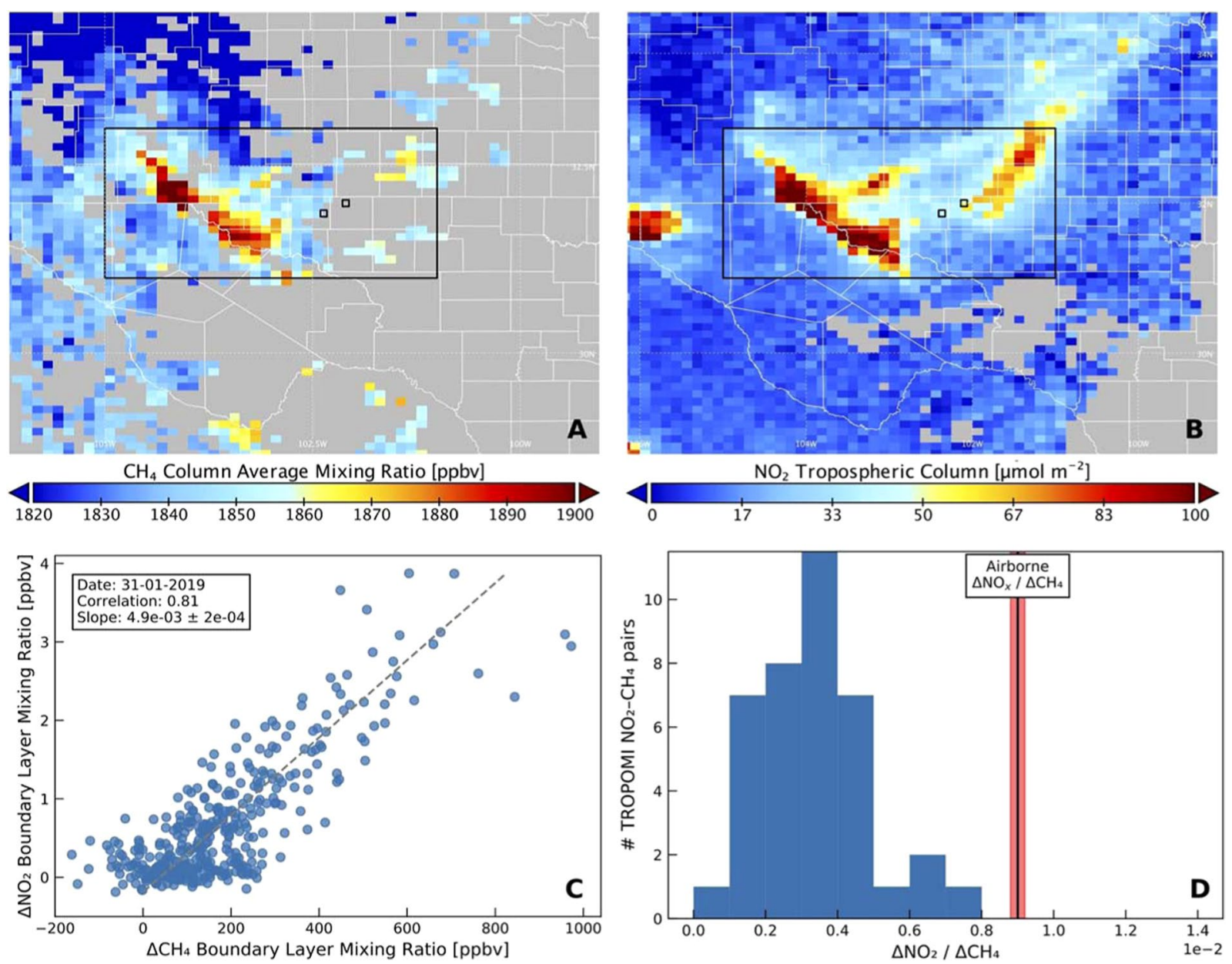

Figure 5. Correlation between TROPOMI methane and $\mathrm{NO}_{2}$ columns in the Permian Basin. Columns for (A) methane and (B) tropospheric $\mathrm{NO}_{2}$ data from 31 January 2019 show enhancements in the same areas. (C) Scatter plot of $\mathrm{NO}_{2}$ vs. methane boundary layer mixing ratios calculated from the TROPOMI columns in the Permian Basin box highlighted by the thick black line; the $\mathrm{NO}_{2}$ enhancement west of the box is due to El Paso-Ciudad Juarez. $\mathrm{NO}_{2}$ and methane were correlated on 31 January with a linear correlation coefficient of 0.81 and an $\mathrm{NO}_{2}$-to- $\mathrm{CH}_{4}$ slope of $(4.9 \pm 0.2) \times 10^{-3}$. (D) A histogram of $\mathrm{NO}_{2}$-to- $\mathrm{CH}_{4}$ slopes from all overpasses with $\mathrm{r}>0.4$ between 1 December 2018 and 31 March 2019 shows a distribution that is limited at the high end by the $\mathrm{NO}_{2^{-}}$ to- $\mathrm{CH}_{4}$ slope of $(9.0 \pm 0.2) \times 10^{-3}$ observed from airborne measurements indicated by the line and the red area.

industrial activities to be separated. The current analysis also needs to be extended to other oil and production regions in North America once more data are available, and to production regions outside of North America.

The TROPOMI data will likely also allow the quantification of methane and $\mathrm{NO}_{2}$ emissions through inverse modeling. For methane, this can possibly be done directly, although the accurate modeling of tropopause height, stratospheric removal and boundary conditions of the modeling domain are all significant challenges ${ }^{31}$. An indirect way of determining methane emissions may be through the inverse modeling of $\mathrm{NO}_{\mathrm{x}}$ emissions $^{32,33}$ and the scaling to methane through observed $\mathrm{NO}_{2} / \mathrm{CH}_{4}$ ratios.

Finally, in-situ measurements in oil and gas production regions and coordinated airborne measurements would allow further verification of the results obtained in this analysis and extension to other regions.

\section{Methods}

TROPOMI satellite instrument. TROPOMI is the single payload on board of the EU Copernicus Sentinel-5 Precursor satellite, which was launched in October 2017 into a Sun-synchronous orbit with an overpass time of 13:30 local solar time ${ }^{21}$. TROPOMI is a push-broom imaging spectrometer with a swath width of $2,600 \mathrm{~km}$ and a ground pixel of $3.5-7 \times 7 \mathrm{~km}^{2}$ at the sub-satellite point. TROPOMI has two spectrometer modules, the first covering bands in the ultraviolet, visible, and near-infrared (NIR) and the second dedicated to the shortwave infrared (SWIR) band centered around $2.3 \mu \mathrm{m}$.

TROPOMI methane retrieval. We use the TROPOMI operational $\mathrm{CH}_{4}$, data product $(\mathrm{Hu} 2016)$ version 1.2 (https://doi.org/10.5270/S5P-3p6lnwd), which implements the RemoTec retrieval algorithm ${ }^{34,35}$. The operational algorithm uses a two-band retrieval approach using the NIR and SWIR bands. The SWIR band contains the $\mathrm{CH}_{4}$ information and the NIR band is used for correction for aerosols. From the operational data we use bias-corrected 
column average mixing ratios, with a quality value larger than 0.5 , which filters the data for low data quality, high solar and viewing zenith angles and high aerosol loading. We estimate the uncertainty in the column average $\mathrm{CH}_{4}$ mixing ratios by multiplying the reported retrieval precision with a factor of 2 , as recommended by the data providers.

For the maps shown in Fig. 1, and for the comparisons between $\mathrm{NO}_{2}$ and $\mathrm{CH}_{4}$ we constructed daily data on a $0.1^{\circ} \times 0.125^{\circ}$ latitude-longitude grid. For the $\mathrm{CH}_{4}$ data, only retrievals with a surface albedo larger than 0.05 are included in the gridded data.

TROPOMI NO 2 retrieval. We use the TROPOMI operational $\mathrm{NO}_{2}$ data product version 1.2 (https:// doi.org/10.5270/S5P-s4ljg54). The $\mathrm{NO}_{2}$ processing system uses a DOAS (Differential Optical Absorption Spectroscopy) fit on the visible spectra. The tropospheric $\mathrm{NO}_{2}$ column is determined by subtracting the stratospheric $\mathrm{NO}_{2}$ column amount and corrections for the effects of surface reflectance and clouds ${ }^{36}$. We use the $\mathrm{NO}_{2}$ retrievals with a quality value larger than 0.75 .

In-situ measurements in the uintah basin. In-situ measurements of $\mathrm{CH}_{4}$ (along with $\mathrm{CO}_{2}$ and $\mathrm{H}_{2} \mathrm{O}$ ) at three sites in the Uintah Basin have been carried out by the University of Utah since 2015 using Los Gatos Ultra-Portable Greenhouse Gas Analyzers (Los Gatos Research Inc., San Jose, CA). The analyzers take data every 10 seconds and are calibrated every three hours with reference gas cylinders traceable to the World Meteorological Organization scale. For more details regarding the measurement setup and instrument uncertainties, we refer the reader to Foster et al. ${ }^{10}$ and Bares et al. ${ }^{37}$.

TCCON measurements at lamont. Measurements from the Total Carbon Column Observing Network (TCCON) at Lamont, Oklahoma $(36.604 \mathrm{~N}, 97.486 \mathrm{~W})$ are used to evaluate TROPOMI data for a location that is closest to the region of interest (Fig. S3). TCCON consists of a network of ground-based Fourier-Transform Infrared Spectrometers that record spectra of the sun and allow accurate and precise retrievals of column-averaged abundances of atmospheric constituents including $\mathrm{CH}_{4}$. Data are available at https://doi.org/10.14291/tccon. ggg2014.lamont01.R1/1255070 38

Permian basin production data. Oil and natural gas production data were obtained at the well level using the Drillinginfo tool provided by Enverus and were averaged over the same $0.1^{\circ} \times 0.125^{\circ}$ latitude-longitude grid boxes as used for the methane columns. Total production volumes of oil and natural gas for the U.S. and for the Permian Basin were also obtained from the U.S. Energy Information Administration (www.eia.gov) and for Utah from the Utah Division of Oil, Gas and Mining (oilgas.ogm.utah.gov) summing the data for the Uintah and Duchesne counties. Drill rig counts are from Baker Hughes (bakerhughes.com) with only statewide data available for Utah.

\section{Data availability}

TROPOMI methane (https://doi.org/10.5270/S5P-3p6lnwd) and $\mathrm{NO}_{2}$ data (https://doi.org/10.5270/S5P-s4lig54) are publicly available. The in-situ methane measurements in the Uintah Basin are available at https://air.utah.edu and the raw data are provided upon request by J.C. Lin. The TCCON data are publicly available at https://doi. org/10.14291/tccon.ggg2014.lamont01.R1/1255070.

Received: 11 July 2019; Accepted: 6 January 2020;

Published online: 28 January 2020

\section{References}

1. IPCC. Observations: Atmosphere and Surface (2013).

2. Schwietzke, S. et al. Upward revision of global fossil fuel methane emissions based on isotope database. Nature 538, 88-91 (2016).

3. Turner, A. J., Frankenberg, C. \& Kort, E. A. Interpreting contemporary trends in atmospheric methane. Proceedings of the National Academy of Sciences 116, 2805-2813 (2019).

4. Alvarez, R. A. et al. Assessment of methane emissions from the U.S. oil and gas supply chain. Science 361, 186-188 (2018).

5. Maasakkers, J. D. et al. Gridded National Inventory of U.S. Methane Emissions. Environmental Science \& Technology 50, 13123-13133 (2016).

6. Turner, A. J. et al. A large increase in U.S. methane emissions over the past decade inferred from satellite data and surface observations. Geophysical Research Letters 43, 2218-2224 (2016).

7. Lan, X. et al. Long-Term Measurements Show Little Evidence for Large Increases in Total U.S. Methane Emissions Over the Past Decade. Geophysical Research Letters 46, 4991-4999 (2019).

8. Nisbet, E. G. et al. Rising atmospheric methane: 2007-2014 growth and isotopic shift. Global Biogeochemical Cycles 30, 1356-1370 (2016).

9. Petron, G. et al. Hydrocarbon emissions characterization in the Colorado Front Range: A pilot study. Journal of Geophysical Research - Atmospheres 117, D04304 (2012).

10. Foster, C. S. et al. Confirmation of elevated methane emissions in Utah's Uintah Basin with ground-based observations and a highresolution transport model. Journal of Geophysical Research - Atmospheres 15, 411-19 (2017).

11. Karion, A. et al. Methane emissions estimate from airborne measurements over a western United States natural gas field. Geophysical Research Letters 40, 4393-4397 (2013).

12. Lavoie, T. N. et al. Spatiotemporal variability of methane emissions at oil and natural gas operations in the Eagle Ford basin. Environmental Science \& Technology 51, 8001-8009 (2017).

13. Peischl, J. et al. Quantifying methane and ethane emissions to the atmosphere from Central and Western U.S. oil and natural gas production regions. Journal of Geophysical Research - Atmospheres 123, 7725-7740 (2018).

14. Frankenberg, C. et al. Airborne methane remote measurements reveal heavy-tail flux distribution in Four Corners region. Proceedings of the National Academy of Sciences 113, 9734-9739 (2016).

15. Schneising, O. et al. Remote sensing of fugitive methane emissions from oil and gas production in North American tight geologic formations. Earths Future 2, 548-558 (2014) 
16. Kort, E. A. et al. Four corners: the largest US methane anomaly viewed from space. Geophysical Research Letters 41, 6898-6903 (2014).

17. Thompson, D. R. et al. Space-based remote imaging spectroscopy of the Aliso Canyon $\mathrm{CH}_{4}$ superemitter. Geophysical Research Letters 43, 6571-6578 (2016).

18. Conley, S. A. et al. Methane emissions from the 2015 Aliso Canyon blowout in Los Angeles, CA. Science 351, 1317-1320 (2016).

19. Varon, D. J. et al. Satellite discovery of anomalously large methane point sources from oil/gas production. Geophysical Research Letters In press (2019).

20. Levelt, P. F. et al. The Ozone Monitoring Instrument: overview of 14 years in space. Atmospheric Chemistry and Physics 18, 5699-5745 (2018).

21. Veefkind, J. P. et al. TROPOMI on the ESA Sentinel-5 Precursor: A GMES mission for global observations of the atmospheric composition for climate, air quality and ozone layer applications. Remote Sensing of Environment 120, 70-83 (2012).

22. Hu, H. et al. Toward global mapping of methane with TROPOMI: first results and intersatellite comparison to GOSAT. Geophysical Research Letters 45, 3682-3689 (2018).

23. Nevison, C. et al. Nitrous oxide emissions estimated with the CarbonTracker-Lagrange North American regional inversion framework. Global Biogeochemical Cycles 32, 463-485 (2018).

24. Duncan, B. N. et al. A space-based, high-resolution view of notable changes in urban NO xpollution around the world (2005-2014). Journal of Geophysical Research - Atmospheres 121, 976-996 (2016).

25. Edwards, P. M. et al. High winter ozone pollution from carbonyl photolysis in an oil and gas basin. Nature 514, 351-354 (2014).

26. Ahmadov, R. et al. Understanding high wintertime ozone pollution events in an oil and natural gas-producing region of the western US. Atmospheric Chemistry and Physics 15, 411-429 (2015).

27. Foster, C. S. et al. Quantifying methane emissions in the Uintah Basin during wintertime stagnation episodes. Elementa - Science of the Anthropocene 7, 24 (2019).

28. Neemann, E. M., Crosman, E. T., Horel, J. D. \& Avey, L. Simulations of a cold-air pool associated with elevated wintertime ozone in the Uintah Basin, Utah. Atmospheric Chemistry and Physics 15, 135-151 (2015).

29. Gorchov Negron, A. M. et al. Development of a fuel-based oil and gas inventory of nitrogen oxides emissions. Environmental Science \& Technology 52, 10175-10185 (2018)

30. Warneke, C. et al. Volatile organic compound emissions from the oil and natural gas industry in the Uintah Basin, Utah: oil and gas well pad emissions compared to ambient air composition. Atmospheric Chemistry and Physics 14, 10977-10988 (2014).

31. Jacob, D. J. et al. Satellite observations of atmospheric methane and their value for quantifying methane emissions. Atmospheric Chemistry and Physics 16, 14371-14396 (2016).

32. Mijling, B. \& van der, A. R. J. Using daily satellite observations to estimate emissions of short-lived air pollutants on a mesoscopic scale. Journal of Geophysical Research - Atmospheres 117, D17302 (2012).

33. Ding, J., van der, A. R. J., Mijling, B. \& Levelt, P. F. Space-based $\mathrm{NO}_{\mathrm{x}}$ emission estimates over remote regions improved in DECSO. Atmospheric Measurement Techniques 10, 925-938 (2017).

34. Butz, A. et al. Toward accurate $\mathrm{CO}_{2}$ and $\mathrm{CH}_{4}$ observations from GOSAT. Geophysical Research Letters 38, L14812 (2011).

35. Hu, H. et al. The operational methane retrieval algorithm for TROPOMI. Atmospheric Measurement Techniques 9, 5423-5440 (2016).

36. Boersma, K. F. et al. Improving algorithms and uncertainty estimates for satellite $\mathrm{NO}_{2}$ retrievals: results from the quality assurance for the essential climate variables (QA4ECV) project. Atmospheric Measurement Techniques 11, 6651-6678 (2018).

37. Bares, R. et al. The Utah urban carbon dioxide (UUCON) and Uintah Basin greenhouse gas networks: Instrumentation, data and measurement uncertainty. Earth System Science Data Discussions 1-34 (2019).

38. Wennberg, P. O. et al. TCCON data from Lamont (US), Release GGG2014R1. (2016).

\section{Acknowledgements}

This work contains modified Copernicus Sentinel data 2018-2019. We are grateful to the SRON and KNMI science teams for producing and providing the data, which are funded by the Netherlands Space Office under the TROPOMI science contract. Oil and gas production data in Figures 3 and 4 were provided by and used with permission from Drillinginfo. JdG thanks M. Trainer for helpful suggestions and M. Dechesne for help with creating the oil and gas production maps in an earlier version of Figure 3. J.C.L. is grateful to R. Bares, B. Fasoli, M. Garcia, and S. Lyman for their contributions to maintaining the surface observations in the Uintah Basin. We acknowledge funding from the Rocky Mountain Institute and from the NASA ACMAP program (award \# 80NSSC19K0979). Funding from NOAA Climate Program Office's Atmospheric Chemistry, Carbon Cycle, and Climate program, award \#NA14OAR4310138 for the work in the Uintah Basin is also acknowledged. We thank P. Wennberg for the TCCON data in Figure S3. The TCCON measurements at Lamont, Oklahoma are supported by NASA's Orbiting Carbon Observatory Program, NASA's Carbon Cycle Research Program, and the Department of Energy Atmospheric Radiation Monitoring Project.

\section{Author contributions}

J.d.G. and J.P.V. conceived and conducted the research and wrote the paper. J.C.L. provided in-situ methane data from the Uintah Basin and gave feedback on the manuscript. J.L. provided Figure S3 and essential insights into the methane retrievals and gave feedback on the manuscript. B.D. and E.R. analyzed production data and the correlation with methane columns (Figure 4). P.F.L. managed the project and gave feedback on the manuscript.

\section{Competing interests}

The authors declare no competing interests.

\section{Additional information}

Supplementary information is available for this paper at https://doi.org/10.1038/s41598-020-57678-4.

Correspondence and requests for materials should be addressed to J.A.d.G.

Reprints and permissions information is available at www.nature.com/reprints.

Publisher's note Springer Nature remains neutral with regard to jurisdictional claims in published maps and institutional affiliations. 
(c) (i) Open Access This article is licensed under a Creative Commons Attribution 4.0 International License, which permits use, sharing, adaptation, distribution and reproduction in any medium or format, as long as you give appropriate credit to the original author(s) and the source, provide a link to the Creative Commons license, and indicate if changes were made. The images or other third party material in this article are included in the article's Creative Commons license, unless indicated otherwise in a credit line to the material. If material is not included in the article's Creative Commons license and your intended use is not permitted by statutory regulation or exceeds the permitted use, you will need to obtain permission directly from the copyright holder. To view a copy of this license, visit http://creativecommons.org/licenses/by/4.0/.

(C) The Author(s) 2020 